\title{
Factors associated with home death for individuals who receive home support services: a retrospective cohort study Kevin Brazil *1, Michel Bedard ${ }^{2}$ and Kathleen Willison ${ }^{3}$
}

Address: ${ }^{1}$ Department of Clinical Epidemiology and Biostatistics, Faculty of Health Sciences, McMaster University. Address: 105 Main St. E., Level PI. Hamilton, Ontario, L8N 1G6 Canada, ${ }^{2}$ Lakehead Psychiatric Hospital, 580 North Algoma Street, Thunder Bay, ON. P7B 5G4, Ontario, Canada and ${ }^{3}$ Hamilton-Wentworth Victorian Order of Nurses, 414 Victoria Ave. N. Hamilton, ON L8L 5G8, Ontario, Canada

E-mail: Kevin Brazil* - brazilk@mcmaster.ca; Michel Bedard - michel.bedard@lakeheadu.ca; Kathleen Willison - Willisk@mcmaster.ca ${ }^{*}$ Corresponding author

This article is available from: http://www.biomedcentral.com/I472-684X/I/2

(C) 2002 Brazil et al; licensee BioMed Central Ltd. Verbatim copying and redistribution of this article are permitted in any medium for any purpose, provided this notice is preserved along with the article's original URL.

\begin{abstract}
Objectives: To determine the factors associated with a home death among older adults who received palliative care nursing home services in the home.

Methods: The participants in this retrospective cohort study were $15 \mid$ family caregivers of patients who had died approximately 9 months prior to the study telephone interview. The interview focused on the last year of life and covered two main areas, patient characteristics and informal caregiver characteristics.

Results: Odds ratios [OR] and $95 \%$ confidence intervals $[95 \% \mathrm{Cl}]$ were used to determine which of the 15 potential informal caregiver and seven patient predictor variables were associated with dying at home. Multivariate analysis revealed that the odds of dying at home were greater when the patient lived with a caregiver $[O R=7.85 ; 95 \% \mathrm{Cl}=(2.35,26.27)]$, the patient stated a preference to die at home $[\mathrm{OR}=6.5 \mathrm{I} ; 95 \% \mathrm{Cl}=(2.66,15.95)]$, and the family physician made home visits [OR $=4.79 ; 95 \% \mathrm{Cl}=(1.97,1 \mathrm{I} .64)]$. However the odds were lower for patients who had caregivers with fair to poor health status $[O R=0.22 ; 95 \% \mathrm{Cl}=(0.07,0.65)]$ and for patients who used hospital palliative care beds $[\mathrm{OR}=0.3 \mathrm{I} ; 95 \% \mathrm{Cl}=(0.12,0.80)]$.

Discussion: The findings suggest that individuals who indicated a preference to die at home and resided with a healthy informal caregiver had better odds of dying at home. Home visits by a family physician were also associated with dying at home.
\end{abstract}

Current government policy in Canada is pressing for more and better care of the terminally ill in the community [13]. Several factors contribute to the re-emergence of home death, including: preference of the terminally ill and their families to remain in the home, recognition of the limited benefits found in medical care, improvements in home based medical technology and pharmacology, and hospi- tal restructuring resulting in the closure of hospital beds $[4,5]$. Related to this shift is an increasing elderly population which provides an impetus for the development of home based palliative care programs $[6,7]$. Despite the above, fewer people are able to die at home than would wish to do so. While death at home is preferred by one half or more of terminally ill patients $[8,9]$, approximately $25 \%$ of people in Britain currently die at home [10]. Low- 
er percentages have been reported in the United States and Australia [11].

The literature illustrates a number of factors needed to support a death at home. These include: the patients' and caregivers' desire for a home death, availability of skilled support 24 hours a day, health of the participating caregiver, and sufficient financial resources to allow caregiving to occur at home $[12,13]$.

The majority of published studies on the determinants of place of death focus on the relationships between sociodemographic and support network characteristics of the patient and place of death $[14,15]$. Studies investigating place of death for patients who received palliative home care reveal that patients with a primary caregiver $[16,17]$ and those receiving additional home support [13] are more likely to die at home. Despite the volume of research in this area definite conclusions on the determinants of place of death remain elusive [15]. Identifying these determinants could improve supportive community care for the terminally ill.

The purpose of this retrospective cohort study was to determine what patient and informal caregiver characteristics were associated with a home death among older adults receiving palliative care nursing services in the home. The results provide information which can assist in future planning and implementation of sustainable community-based programs tailored specifically to the needs of the terminally ill and their family caregivers.

\section{Method}

Family caregivers were recruited into the study over a two year period [1997-99] through one of two community nursing agencies providing palliative care nursing services in homes located in an urban region in the province of Ontario, Canada. Patients were placed on the palliative case load of the participating agencies if they met one of the several criteria: identified end stage disease, oncology diagnosis indicated metastases, oncology patient was expected to undergo chemo or radiation therapy and would require symptom management, or presented complex psychosocial needs. The focus of services provided by the nursing agencies was physical symptom management and psychosocial and spiritual support. Palliative care nurses could also assess and facilitate referrals to other appropriate services.

Inclusion criteria for study participants were that: the deceased was 50 years or older and the family caregiver could not only communicate well in english, but would provide informed consent. Caregivers were excluded from the study if the patient had dementia not due to malignancy and/or medication. Patients with dementia due to these two causes were excluded from the study as investigators felt that they represented a unique subpopulation presenting special needs which require separate considerations. Family caregivers were defined as relatives of the deceased who provided care to that individual on a regular basis, and did not receive remuneration for such services.

\section{Procedure}

Family caregivers identified according to the above eligibility criteria were contacted by the nursing agency who explained the study to them. Once permission was obtained to release the names of interested caregivers to the study team a research assistant contacted participants to obtain consent and complete a telephone interview. Interviewers had undergraduate degrees in gerontology or the health sciences. Interviewer training included mock interviews and quality assurance assessments to ensure interview protocols were followed. Ethics approval was obtained from the local ethics board.

\section{Interview schedule}

The interview procedure built upon that used by Addington-Hall and McCarthy [18] and covered the last year of life. Data collected covered two main areas: patient characteristics, and informal caregiver characteristics. Patient characteristics included: sex, age, marital status, diagnosis, dependence in activities of daily living [ADL] [bathing, mobility, dressing, toileting and assistance at night], length of time assistance needed in ADL, living arrangements, preferred place of death, and place of death. Informal caregiver characteristics included: sex, gender, education, employment status, self report of health status [excellent, very good, good, fair, poor], caregiving experience, and formal services used.

To catalogue "preferred place of death" respondents were asked whether the care recipient expressed a preferred place to die and if so, where such was located. The caregiving experience was assessed by the Caregiver Reaction Assessment [CRA]. A 24-item scale, the CRA measures the reaction of family caregivers caring for older adults with physical and mental impairments [19]. Respondents used a five point likert scale ranging from strongly disagree to strongly agree as indicators of their agreement with 24 sentences. In completing the CRA, respondents were instructed to, "Think back to your caregiver experience with Try to remember how you felt most of the time when you were caring for him/her". The scoring of positively worded sentences was reversed such that higher scores indicated more negative impacts of caregiving. The total possible score ranged from 24 [no negative impact] to 120 [immense negative impact]. Furthermore, the instrument included five subscales which measured: the extent to which caregiving impacts self-esteem [range of 7- 
35]; lack of family support [5-25]; impact on finances [315]; impact on schedule [5-25]; and, impact on health, which assessed the caregiver's physical capability and energy to provide care [4-20]. The instrument was multidimensional, factorially invariant across different patient groups, and factorially invariant across repeated measurement occasions [20]. In a multicenter study of partners of patients with cancer, reliability analysis of the CRA showed Cronbach's alphas between .62 and .83 for the separate subscales, indicating sufficient internal consistencies [21] . The study also found that the subscales represented conceptually different dimensions within the caregiving situation and supported the construct validity of the subscales. The CRA was preferred above other caregiver burden instruments for this study because other instruments were developed for caregivers of persons with mental impairment only or addressed only the negative consequences of caregiving [22-24].

\section{Statistical analysis}

Means, standard deviations and frequencies were used to describe patient and informal caregiver characteristics. Univariate odds ratios [OR] along with their 95\% confidence intervals [95\% CI] were used to determine which of the patient and informal caregiver variables were associated with a home death. The independent contribution of predictor variables was then assessed by a multivariate logistic regression. For the multivariate logistic regression, we used statistically significant variables according to univariate analyses and those considered by the investigators to be theoretically significant. Theoretical significant variables included the age and gender of the patient and caregiver, caregiver employment status and whether the patient received home making services. These variables were selected as previous research has revealed their significance in understanding patterns of caregiving [25].

For the purpose of logistic regression, a composite score of caregiver assistance provided to the patient on ADL was obtained by considering how long the assistance had been provided. The score could be one if the assistance was less than one month in duration, two for one to three months, three for three to six months, four for six to 12 months, and five for greater than 12 months. For example, if the patient had been receiving bathing assistance for more than six months but less than 12 , a score of four would have been assigned for this type of need. The scores for all five activities were then added to form the composite score. The minimum possible score was zero, the maximum possible was 30. SPSS [version 9.0 for Windows, SPSS Inc., Chicago, 1998] was used for statistical computations and a probability level of 0.05 selected to determine statistical significance [i.e., the 95\% CI does not include 1.0].
Table I: Characteristics of study population $(n=\mid 5 I)$

N (\%)

$\begin{array}{lc}\text { Patient Characteristics } & \\ \text { Sex } & \\ \text { • women } & 63(41.7) \\ \text { - men } & 88(58.3) \\ \text { Diagnosis } & \\ \text { - cancer } & 124(82.1) \\ \text { - other } & 26(17.2) \\ \text { Setting of death } & \\ \text { - home } & 95(62.9) \\ \text { - hospital } & 54(35.7) \\ \text { - nursing home } & 1(.7) \\ \text { - other } & 1(.7) \\ \text { Caregiver Characteristics } & \\ \text { Sex } & \\ \text { - women } & 119(78.8) \\ \text { - men } & 32(21.2) \\ \text { Relationship to patient } & \\ \text { - spouse } & 99(65.6) \\ \text { - child } & 46(30.4) \\ \text { - extended family } & 6(3.9) \\ \text { Lived with patient } & 130(86) \\ \text { Not employed } & 102(67.5) \\ \text { Education completed } & \\ \text { - elementary } & \\ \text { - high school } & 45(29.8) \\ \text { - college } & 57(37.7) \\ \text { - university } & 30(19.8) \\ & 19(12.5) \\ \end{array}$

\section{Results}

Participants included 151 family caregivers [consent rate of $51 \%$ ] of patients who had died approximately 9 months prior to the study interview. The average age of patients was 71 years $[\mathrm{SD}=9.34]$ and 61 years $[\mathrm{SD}=$ 13.56] for the caregivers. Other characteristics of the study population are shown in Table 1.

Eighty-nine percent of caregivers reported the patient experienced some degree of functional restriction. The number of caregivers providing assistance in specific functional activities was: bathing, 133 [88\%]; mobility, 123 [81\%]; dressing and undressing, 114 [76\%]; toileting, 101 [67\%] and, assistance at night 97 [64\%]. Since study participants were recruited through visiting nursing agencies, all were receiving home nursing visits. The three most frequently used services reported by caregivers included house calls by a family physician, 89 [59\%]; home making services, 84 [56\%]; and hospital palliative care services 37 [25\%].

Unadjusted univariate OR and corresponding 95\% confidence intervals are presented in Tables 2 and 3. The refer- 
Table 2: The association of patient variables and home death

\begin{tabular}{|c|c|c|c|c|c|c|}
\hline \multirow[t]{2}{*}{ Variable } & \multicolumn{2}{|c|}{ Home death } & \multicolumn{2}{|c|}{ Univariate } & \multicolumn{2}{|c|}{ Multivariate } \\
\hline & Yes & No & OR & $95 \% \mathrm{Cl}$ & OR & $95 \% \mathrm{Cl}$ \\
\hline \multicolumn{7}{|l|}{ Gender } \\
\hline - female & $40(62.5)$ & $23(37.5)$ & 1.04 & $0.53,2.04$ & NS & \\
\hline - male & $55(63.5)$ & $33(36.5)$ & 1.00 & $1.00,1.00$ & & \\
\hline \multicolumn{7}{|l|}{ Age } \\
\hline • 50-64 & $25(69.4)$ & II(30.6) & 1.00 & $1.00,1.00$ & NS & \\
\hline • 65-74 & $35(61.4)$ & $22(38.6)$ & 0.70 & $0.29,1.70$ & & \\
\hline$\cdot 75+$ & $35(60.3)$ & $23(39.7)$ & 0.67 & $0.28,1.62$ & & \\
\hline \multicolumn{7}{|c|}{ Marital status } \\
\hline - spouse & $64(64.6)$ & $35(35.4)$ & 1.24 & $0.62,2.47$ & & \\
\hline - other & $31(59.6)$ & $21(40.4)$ & 1.00 & $1.00,1.00$ & & \\
\hline \multicolumn{7}{|l|}{ Diagnosis } \\
\hline - cancer & 78 (62.9) & $46(37.1)$ & 0.90 & $0.37,2.18$ & & \\
\hline - other & $17(65.4)$ & $9(34.6)$ & 1.00 & $1.00,1.00$ & & \\
\hline \multicolumn{7}{|c|}{ Dependence in ADL } \\
\hline - high & $43(6 I .4)$ & $27(38.6)$ & 0.87 & $0.44,1.74$ & & \\
\hline - low & $44(64.7)$ & $24(35.3)$ & 1.00 & $1.00,1.00$ & & \\
\hline \multicolumn{7}{|c|}{ Lived with caregiver } \\
\hline - yes & $88(67.7)$ & $42(32.3)$ & 4.19 & $1.57,11.15$ & 7.85 & $\begin{array}{c}2.35,26 \\
.27\end{array}$ \\
\hline - no & 7 (33.3) & $14(66.7)$ & 1.00 & $1.00,1.00$ & & \\
\hline \multicolumn{7}{|c|}{ Stated preference } \\
\hline -yes & $74(79.6)$ & $19(20.4)$ & 6.86 & $3.29,14.32$ & 6.51 & $\begin{array}{l}2.66 \\
15.95\end{array}$ \\
\hline - no & $21(36.2)$ & $37(63.8)$ & 1.00 & 1.00 & & \\
\hline
\end{tabular}

ence category is indicated by an OR of 1.00 and a $95 \%$ CI of $1.00,1.00$. The multivariate model revealed that the odds of dying at home were greater when the patient lived with the caregiver $[\mathrm{OR}=7.85 ; 95 \% \mathrm{CI}=2.35,26.27]$, the patient stated a preference to die at home $[\mathrm{OR}=6.51 ; 95 \%$ $\mathrm{CI}=2.66,15.95]$, and the family physician made home visits $[\mathrm{OR}=4.79 ; 95 \% \mathrm{CI}=1.97,11.64]$. The odds were lower for patients who used hospital palliative care beds $[\mathrm{OR}=0.31 ; 95 \% \mathrm{CI}=0.12,0.80]$ or had caregivers with fair to poor health status $[\mathrm{OR}=.22 ; 95 \% \mathrm{CI}=0.07,0.64]$.

\section{Discussion}

The findings of this study further our understanding of factors associated with home deaths among those who receive palliative nursing care in the home. Individuals who indicated a preference to die at home and resided with a healthy informal caregiver had better odds of dying at home. Home visits by the family physician were also associated with dying at home.

The profile of caregivers and patients in this study is consistent with the research literature. Females are most likely to provide informal care [25]. The estimates range from $60 \%-75 \%$ of informal care in Canada being provided by women [25]. Caregivers are often a spouse or daughters, particularly an eldest daughter [26].

The main limitation of this study is the uncertain generalizability of the findings. The consent rate of $51 \%$ is consistent, if not better, than previously reported in bereavement studies [27]. Strobe \& Strobe [27] conducted a review of 21 bereavement studies similar in design to the present study and reported that half of these had accrual rates of less than $50 \%$. However, the authors determined that depression was a factor in whether individuals participated. Specifically, men who were less depressed agreed to participate while women who were more depressed did so. The authors explained this sex difference in terms of sex roles in coping styles and norms for exhibiting emotions. Hence, non-participants may have different response patterns than participants. Further replication with prospective designs may resolve this issue and strengthen causal linkages on the present study findings.

The strength of the statistical associations in this study establish clear service implications. As dying at home is dependent on caregivers' capacity to manage domestic situations, recognition of the vital role families and other 
Table 3: The association of caregiver variables and home death

\begin{tabular}{|c|c|c|c|c|c|c|}
\hline \multirow[t]{2}{*}{ Variable } & \multicolumn{2}{|c|}{ Home death } & \multicolumn{2}{|c|}{ Univariate } & \multicolumn{2}{|c|}{ Multivariate } \\
\hline & Yes & No & OR & $95 \% \mathrm{Cl}$ & OR & $95 \% \mathrm{Cl}$ \\
\hline \multicolumn{7}{|l|}{ Gender } \\
\hline - female & $75(63.0)$ & $44(37.0)$ & 1.02 & $0.46,2.29$ & NS & \\
\hline - male & $20(62.5)$ & $12(37.5)$ & 1.00 & $1.00,1.00$ & & \\
\hline \multicolumn{7}{|l|}{ Age } \\
\hline$\bullet<50$ & $20(60.6)$ & $13(39.4)$ & 1.00 & $1.00,1.00$ & NS & \\
\hline • 50-64 & $27(57.4)$ & $20(42.6)$ & 0.88 & $0.35,2.17$ & & \\
\hline • $65-74$ & $34(69.4)$ & $15(30.6)$ & 1.47 & $0.58,3.72$ & & \\
\hline$\cdot 75+$ & $13(61.9)$ & $8(38.1)$ & 1.06 & $0.34,3.25$ & & \\
\hline \multicolumn{7}{|l|}{ Education } \\
\hline • > high school & $36(67.9)$ & $17(32.1)$ & 1.40 & $0.69,2.83$ & & \\
\hline - other & $59(60.2)$ & $39(39.8)$ & 1.00 & $1.00,1.00$ & & \\
\hline \multicolumn{7}{|l|}{ Employment } \\
\hline - full-time & II (47.8) & $12(52.2)$ & 0.48 & $0.20,1.18$ & NS & \\
\hline - other & $84(65.6)$ & $44(34.4)$ & 1.00 & $1.00,1.00$ & & \\
\hline \multicolumn{7}{|l|}{ Health status } \\
\hline - excellent/very good & $46(74.2)$ & $16(25.8)$ & 1.00 & $1.00,1.00$ & 1 & $\begin{array}{l}1.00 \\
1.00\end{array}$ \\
\hline - good & $33(63.5)$ & $19(36.5)$ & 0.60 & $0.27,1.35$ & 0.64 & $\begin{array}{l}0.22 \\
1.86\end{array}$ \\
\hline • fair/poor & $16(43.2)$ & $21(56.8)$ & 0.27 & $0.11,0.63$ & 0.22 & $\begin{array}{l}0.07 \\
0.65\end{array}$ \\
\hline \multicolumn{7}{|l|}{ Self-esteem } \\
\hline • worst & $21(55.3)$ & $17(44.7)$ & 0.63 & $0.29,1.33$ & & \\
\hline - better & 7I (66.4) & $36(33.6)$ & 1.00 & $1.00,1.00$ & & \\
\hline \multicolumn{7}{|l|}{ Scheduling } \\
\hline - worst & $19(63.3)$ & II(36.9) & 1.02 & $0.45,2.34$ & & \\
\hline - better & $76(62.8)$ & $45(37.2)$ & 1.00 & $1.00,1.00$ & & \\
\hline \multicolumn{7}{|l|}{ Health } \\
\hline - worst & $22(66.7)$ & II (33.3) & 1.23 & $0.55,2.78$ & & \\
\hline - better & $73(61.9)$ & $45(38.1)$ & 1.00 & $1.00,1.00$ & & \\
\hline \multicolumn{7}{|l|}{ Family support } \\
\hline - worst & $19(54.3)$ & $16(45.7)$ & 0.62 & $0.29,1.33$ & & \\
\hline - better & $75(65.8)$ & $39(34.2)$ & 1.00 & $1.00,1.00$ & & \\
\hline \multicolumn{7}{|l|}{ Finance } \\
\hline - worst & $14(60.9)$ & $9(39.1)$ & 0.88 & $0.36,2.20$ & & \\
\hline - better & $81(63.8)$ & $46(36.2)$ & 1.00 & $1.00,1.00$ & & \\
\hline \multicolumn{7}{|l|}{ Other caregiver(s) } \\
\hline - yes & $76(65.5)$ & $40(34.5)$ & 1.60 & $0.74,3.45$ & & \\
\hline$\cdot$ no & $19(54.3)$ & $16(45.7)$ & 1.00 & $1.00,1.00$ & & \\
\hline \multicolumn{7}{|l|}{ Needed more help } \\
\hline - yes & $30(52.6)$ & $27(47.4)$ & 0.49 & $0.25,0.98$ & NS & \\
\hline • no & $63(69.2)$ & $28(30.8)$ & 1.00 & 1.00 & & \\
\hline \multicolumn{7}{|l|}{ Physician home visits } \\
\hline - yes & $68(76.4)$ & $21(23.6)$ & 4.20 & $2.08,8.46$ & 4.79 & $\begin{array}{l}1.97 \\
11.64\end{array}$ \\
\hline$\cdot$ no & $27(46.5)$ & $35(56.5)$ & 1.00 & $1.00,1.00$ & 1.00 & $\begin{array}{l}1.00 \\
1.00\end{array}$ \\
\hline \multicolumn{7}{|l|}{ Homemaking support } \\
\hline - yes & $54(64.3)$ & $30(35.7)$ & 1.14 & $0.59,2.22$ & NS & \\
\hline • no & $4 I(6 I .2)$ & $26(38.8)$ & 1.00 & $1.00,1.00$ & & \\
\hline \multicolumn{7}{|l|}{ Palliative care bed } \\
\hline -yes & $16(43.2)$ & $21(56.8)$ & 0.34 & $0.16,0.72$ & 0.31 & $\begin{array}{c}0.12,0 . \\
80\end{array}$ \\
\hline • no & $79(69.3)$ & $35(30.7)$ & 1.00 & $1.00,1.00$ & 1.00 & $\begin{array}{l}1.00 \\
1.00\end{array}$ \\
\hline
\end{tabular}


caregivers play in the community care system is essential. Family caregivers require support from the "formal care" system in their role of caring for a terminally ill family member. It should be stressed that caregivers in the present study represent an enhanced care group where they had the benefit of experiencing specialized palliative care nursing in the home. The availability of such service in Canada varies from community to community. For many Canadians access to such services becomes "luck of the draw" [1]. Without these supports however caregivers experience stress, burnout and ill health with the inevitable consequence of becoming unable to provide appropriate care to those in need [28]. It is also important to note that family physicians can enable home deaths. However, in these situations, family physicians are confronted by complex, and possibly unfamiliar, end-stage issues, therefore initiatives that enhance the palliative care skills and knowledge base could avert unnecessary institutionalizations [29,30]. Finally, the importance of patient preference in predicting a home death heightens the belief that community care to the terminally ill needs to be client-focussed. Supporting patient and caregiver choices for service and treatment options are essential supportive measures to enable home deaths.

\section{Competing interests}

None declared

\section{References}

I. Canada, Parliament. Standing Senate Committee on Social Affairs, Science and Technology: Quality End-of-Life Care: The Right of Every Canadian. Ottawa, On: Ministry of Supply and Services 2000

2. Health Services Restructuring Commission: Change and Transition: Planning Guidelines and implementation Strategies for Home Care, Long Term Care, Mental Health, Rehabilitation, and Sub-acute Care. Toronto, On: Health Services Restructuring Commission 1998

3. Metropolitan Toronto District Health Council: Palliative Care in Metropolitan Toronto: Building on Our Strengths for the Future. Toronto, On: Metropolitan Toronto District Health Council 1997

4. Sanker A: Images of home death and the elderly patient: romantic versus real. Generations 1993, 17:59-63

5. Stajduhar K, Davies B: Death at home: Challenges for families and directions for the future. I Palliat Care 1998, I4:8-14

6. Brown P, Davies B, Martens N: Families in supportive care - part II: palliative care at home: a viable care setting. J Palliat Care 1990, 6:21-27

7. Steele R, Fitch $M$ : Needs of family caregivers of patients receiving home hospice care for cancer. Oncol Nurs Forum 1996, 23:823-828

8. Dunlop R, Davies R, Hockley J: Preferred vs actual place of death: a hospital palliative care support team experience. $\mathrm{Pal}-$ liat Med 1989, 3: 197-201

9. Townsend J, McCorkle R: Determinants of place of death for terminal cancer patients. Cancer Invest 200I, I 9:165-180

10. Searle C, Cartwright A: The Year Before Death. Averbury, Aldershot. 1994

II. Hunt R, McCaul K: A population-based study of the coverage of cancer patients by hospice services. Palliat Med 1996, I9:5-I2

12. McCorkle R: The four essentials. J Palliat Care 1998, 4:59-6I

13. McWhinney I, Bass M, Vanessa O: Factors associated with location of death (home or hospital) of patients referred to a palliative care team. CMA] 1995, I52:361-267
14. Grande G, Addington-Hall J, Todd C: Place of death and access to home care services: are certain patient groups at a disadvantage? Soc Sci and Med 1998, 47:565-579

15. Tang S, McCorkle R: Determinants of place of death for terminal cancer patients. Cancer Invest 200I, I9:165-180

16. McCusker J, Stoddard A: Effects of an expanding home care program for the terminally ill. Med Care 1987, 25:373-385

17. Dunphy K, Amesbury B: A comparison of hospice and home care patients: patterns of referral, patient characteristics and predictors of place of death. Palliat Med 1990, 4:105-III

18. Addington-Hall J, McCarthy $M$ : Regional study for the dying: methods and sample characteristics. Palliat Med 1995, 9:27-35

19. Given C, Given B, Stommel M, King S, Franklin S: The caregiver reaction assessment (CRA) for persons with chronic physical and mental impairment. Research Nurs Health 1992, I 5:272-283

20. Stommel M, Wang S, Given C, Given B: Confirmatory factor analysis (CFA) as a method to assess measurement equivalence. Research Nurs Health 1992, 15:399-405

21. Niboer C, Triemstra M, Tempelaar R, Sanderman R, van den Bos G: Measuring both negative and positive reactions to giving care to cancer patients: psychometric qualities of the Caregiver Reaction Scale (CRA). Soc Sci \& Med 1998, 48: 1259-1269

22. Novak N, Guest C: Application of a multidimensional caregiver burden inventory. Gerontologist 1989, 29:798-803

23. Kinney J, Stephans M: Caregiving Hassles Scales: assessing the daily hassles of caring for a family member with dementia. Gerontologist 1989, 29:328-332

24. Zarit S, Reever K, Bach-Peterson J: Relatives of the impaired elderly. Correlates of feelings of burden. Gerontologist 1980, 20:649-655

25. Keating N, Fast J, Frederick J, Cranswick J, Perrier C: Eldercare in Canada: Context, content, and consequences. Ottawa: Statistics Canada. Ottawa, Statistics Canada 1999

26. Grunfield E, Glossop R, McDowell I, Danbrook C: Caring for elderly people at home: the consequences to caregiving. CMAJ 1997, I 57(8): I I01- I I05

27. Stroebe M, Stroebe W: Who participates in bereavement research? A review and empirical study. Omega 1989, 20:I-29

28. Mastrian M, Ritter C, Deimling G: Predictors of caregiver health strain. Home Healthc Nurse 1996, I 4:209-317

29. Brenneis C, Bruera E: The Interaction between family physicians and palliative care consultants in the delivery of palliative care: clinical and educational issues. J Palliat Care 1998, | 4:58-6|

30. Schroder C, Seely J: A support network for community physicians. J Palliat Care 1998, I4:98-101

\section{Pre-publication history}

The pre-publication history for this paper can be accessed here:

http://www.biomedcentral.com/1472-684X/1/2/prepub

Publish with BioMed Central and every scientist can read your work free of charge

"BioMedcentral will be the most significant development for disseminating the results of biomedical research in our lifetime." Paul Nurse, Director-General, Imperial Cancer Research Fund

Publish with BMC and your research papers will be:

- available free of charge to the entire biomedical community

- peer reviewed and published immediately upon acceptance

- cited in PubMed and archived on PubMed Central

- yours - you keep the copyright 